\title{
A Second-Order Confirmatory Factor Analysis of the Career Aspirations Scale of Female Thai Students
}

\author{
Buratin Khampirat \\ Suranaree University of Technology \\ Nakhon Ratchasima, Thailand
}

\begin{abstract}
This research investigated the reliability and validity of the Career Aspiration Scale (CAS) of Gregor and O'Brien (2016) which was translated into Thai using multiple translation strategies. The questionnaire was administered to 336 female students in three universities in Thailand. Confirmatory factor analysis was used to verify a three-factor and second-order factor structures for a 24-item measure of CAS (achievement, leadership, and educational aspirations). The scale presented acceptable reliability, convergent, and discriminant validity. The results showed that the Thai version of the CAS could be used as a second-order factor structure better than a three-factor. In a secondorder model, the findings of the study reflected that female Thai students prioritized "achievement aspirations" over "educational aspirations", while "leadership aspirations" were valued the least. Moreover, the mean comparison between first-year and fourth-year students showed that fourth-year students had significantly higher scores than first-year students on all aspects of the CAS.
\end{abstract}

Keywords: Career aspirations; Achievement aspirations; Leadership aspirations; Educational aspirations; Confirmatory factor analysis.

\section{Introduction}

Higher education institutes (HEIs) in Thailand have been very aware of the quality of students who need skills development and readiness to work to prepare for a career pathway by trying to improve and develop students' employability and career skills. Despite the continuous efforts to promote and develop students' work skills for employability and career in the past recent years, the results have not been so successful. Many research studies have explored the underrepresentation of Thai students' work skills to find solutions to this problem. For example, the study of Khampirat (2016) showed that there is a substantial skills gap between the quality of skills demanded and the quality of new graduates. Supported by a 2019's report from the World Economic Forum (WEF, 2019, p. 552) indicating that Thailand was placed 74th out of 141 countries 
in the quality of vocational training ranks, while the skillset of graduates and skills of the future workforce were ranked at 79th and 64th, respectively.

Career aspirations are one of the ways of support in accomplishing future work goals. They are linked to the individual's life (Sidiropoulou-Dimakakou, Mylonas, \& Argyropoulou, 2015), the desire in increase the pool of employability skills, the improvement of workplace performance, and the upward social mobility of professional workers at both national and international levels (Kintrea, Clair, \& Houston, 2011, p.12; McKenzie, ColdwellNeilson, \& Palmer, 2016). According to Sewell, Haller, and Portes (1969) explained that career aspirations serve as a driving force of potential action when associated with a degree of overt behaviors and the craving for personal achievement. However, from a literature survey showed that Thai HEIs lack focuses on the importance of students' career aspirations, which may be due to the Thai cultural emphasis on expressing humility, deference, politeness, and calmness (Komin, 1990, p.164; Powell, Amsbary, \& Hickson, 2014). Therefore, there should be a study of students' career aspirations in the Thai context to identify their future career goals and thoughts about an occupational culture. This is a necessary aspect that should be instilled into the students to demonstrate their innate desire to learn, and that desire will drive them to find out what they want to be, which is relevant to the process of student development and the effect of career choice, achievement, and lifestyle on their future. In the initial stage of career development, having the appropriate instrument for measuring and monitoring the level of career aspirations is important, which will gain a deeper understanding of the motivational intent and occupational dispositions. Detailed information will be used to continually support students to take the development pathways that are likely to lead to fulfilling the longer-term career ambitions and future goals (Kintrea et al., 2011, p. 8).

Even though the complexities of aspirations are difficult to measure, O'Brien (1996) developed a Career Aspiration Scale (CAS) which has been revised (CAS$\mathrm{R})$ and validated as well as used in the context of many countries (for example, USA (Gray \& O'Brien, 2007), Korea (Kim, O'Brien, \& Kim, 2015), Malaysia (Wu, 2007), UK (Fritz \& van Knippenberg, 2017). Because CAS and CAS-R have been developed from a strong theoretical foundation (Byrne, 2012, p.6) and because culture has been proven to have impacts on female's perception on career (Fritz \& van Knippenberg, 2017), the purpose of this study was to examine the factor structure and psychometric properties of the CAS-R as a second-order factor structure when applied to female Thai students. The purpose of this study was to examine the factor structure and psychometric properties of the CAS-R in the Thai version as a second-order factor structure.

\section{O'Brien's career aspiration scale}

In 1996, O'Brien (1996) developed a new CAS with 10-item to assess the value of a person's expectations in having a career. This scale was tested with adolescent females and demonstrated adequate internal consistency reliability (O'Brien, 1996). In 2007, Gray and O'Brien (2007) illustrated the psychometric properties of 
the CAS when applied across five studies. In 2015, CAS was translated into the Korean language and was replicated to test the validation on data from undergraduate Korean women by Kim et al. (2015), the three-factor structure with 18-item was used, which was the alternative model without the reversescored items and demonstrated a good model fit. The three subscales also showed good test-retest reliability over a two-weeks. Kim et al. (2015) mentioned the limitation of the CAS with the 24-item when applied to Korean young women, it was possible that reverse-scored items on this measure might not operate properly with the sample. Later in 2016, Gregor and O'Brien (2016) improved the psychometric properties of the scale, results from confirmatory factor analysis suggested a good model fit of three subscales for assessing leadership, achievement, and educational aspirations.

Despite some limitations, CAS has still become widely recognized and utilized internationally in research on career psychology, it has not just been used in America, but in other countries have also applied such as Malaysia $(\mathrm{Wu}, 2007)$, Canada (Laschinger et al., 2013), Germany (Hoppe \& Fujishiro, 2015), Romania (Ona, 2015), Sri Lanka (Fernando \& Jayasekara, 2015), and UK (Fritz \& van Knippenberg, 2017). Many scholars support the CAS as valid and reliable when applied to adolescents, HEIs, and other samples of this age and adults. For instance, Fritz (2015) employed it to investigate the relationship between uniform and leadership aspiration in students at a university in Sweden, and four items were deleted because of a low internal consistency. In Hong Kong, Cheng and Yuen (2012) assessed the reliability and validity of the Chinese 10item CAS on high school students; the results showed that the scale provides a good fit to the data. In another study conducted by Creed, Tilbury, Buys, and Crawford (2011), four items of CAS were used to survey career aspirations and action behaviors of Australian adolescents in out-of-home care, factor analysis identified a single factor and contained moderate to strong factor loadings. In Thailand, Weeranakint and Sungsanit (2009) applied O'Brien's CAS to investigate the relationship between career aspirations and affective factors of Thai female managers and reported that career aspirations correlated with selfefficacy, as well as a statistically significant difference between organizational types. Based on the previous studies and basis of the relevant literature, they are showing that the CAS-revised version (CAS-R) of Gregor and O'Brien (2016) was a suitable instrument for studying the level of career aspirations. However, the scale should be validated before application in different cultures.

\section{Research methods}

In this section, participants, instruments, procedure, and data analyses were explained. This study was a cross-sectional study (Bethlehem, 1999) and designed to evaluate the psychometric properties of the CAS-R when applied on female Thai students. In this case, second-order confirmatory factor analysis (CFA) was used to verify the CAS-R's three-factor structure. To ensure that the sample size was appropriate for CFA, this study followed the guidelines of at least 200 and 10 or 20 cases per parameter as noted by Kline (2011, pp. 11-12). The steps in the research procedure are shown in Figure 1. 


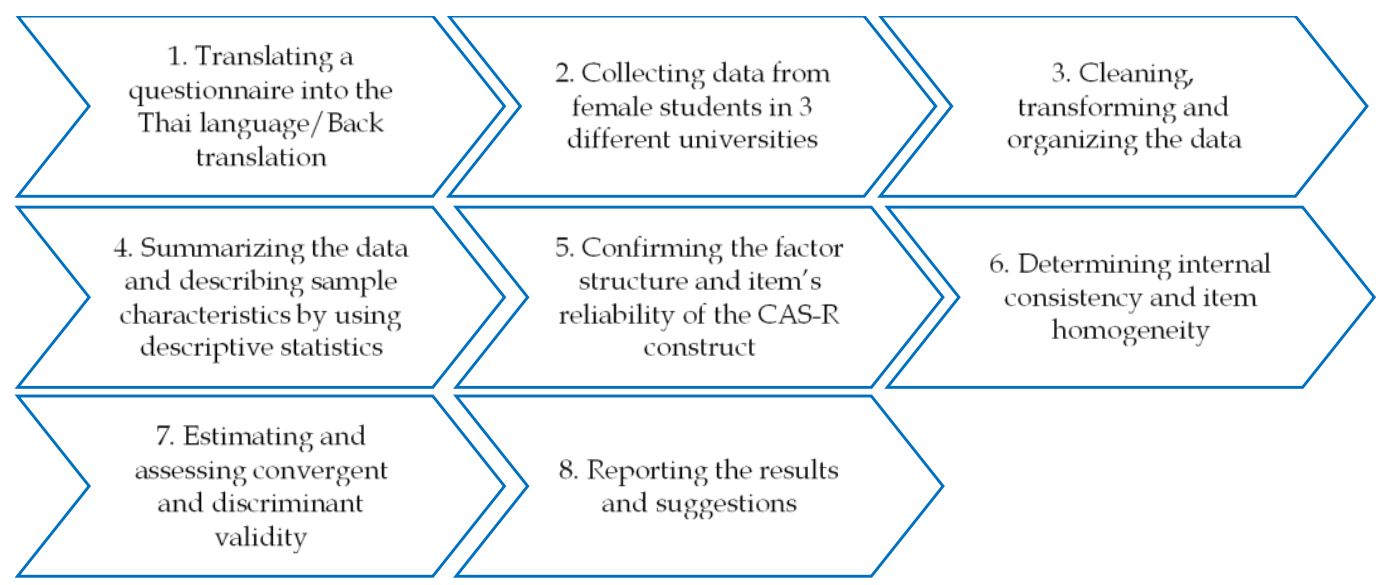

Figure 1. The steps of research method in this study

The following hypotheses are framed and tested in this study:

H1: The hypothesized CAS-R model is an equally good fit for female Thai students.

H2: The female Thai student's scores would confirm the factor structure of the CAS-R.

H3: The CAS-R's three subscales measure unique constructs of the CASR.

H4: The covariance between a set of observed variables can be explained by their latent factor.

H5: The factor structure of the CAS-R shows adequate psychometric properties.

\subsection{Participants}

A total of 336 female students from three different universities in Thailand participated in this study. They were undergraduates studying in various programs, 206 (61.3\%) of them studied Humanities and Social Science Program, $125(37.50 \%)$ studied Information Technology Program, and $4(1.19 \%)$ studied Industrial Technology Program. Regarding the class level, $126(37.50 \%)$ of the participants were first-year, and the rest of 210 (52.50\%) were fourth-year students.

\subsection{Instruments}

This study employed the CAS-R of Gregor and O'Brien (2016) to measure career aspirations, which consists of 24 items to assess three subscales, achievement, leadership, and educational aspirations, as shown in Table 1. The items on the three subscales were scored on a 5-point scale, ranging from 0 (not at all true for me) to 4 (very true for me), the higher scores reflect greater levels of career aspirations. Five negative worded items were reverse scored.

\subsection{Procedure}

The survey was conducted between December 2017 and March 2019 in several ways such as, in classrooms, meeting rooms, and some students were interviewed by phone or email. Participants were asked voluntarily to answer the paper questionnaire. They were informed that their responses would never 
be associated with grading in any subjects and would be kept confidential and anonymous. They took approximately 15-20 minutes to complete the questionnaires.

\subsection{Data analyses}

Descriptive statistics were conducted to assess the normality of distribution. Second-order CFA was used to assess the construct validity of the CAS-R since CAS-R was evaluated as a second-order factor structure to examine the hypothesized relationship between the 24-item (first-order) and the three latent factors (second-order) how well the hypothesized relationship model fitted to the observed data.

The goodness of fit of a statistical model was used to assess how well the theoretical model fitted to the empirical data. A good model fit was indicated by the chi-square per degree of freedom $\left(\chi^{2} / d f<3\right)$ (Kline, 2011, p. 204), the comparative fit index (CFI $\geq 0.90$ ) (Hu \& Bentler, 1999), the Tucker-Lewis index (TLI $\geq 0.90)$ (Hu \& Bentler, 1999), the root mean square error of approximation (RMSEA < 0.06 to 0.08 with $90 \%$ confidence intervals) (Schreiber, Nora, Stage, Barlow, \& King, 2006), and the standardized root mean square residual (SRMR $\leq$ 0.08) (Hu \& Bentler, 1999). The size of standardized factor loading $(\beta>|.5|, p<$ 0.05), the value of the average variance extracted (Gore et al., 2017), and the construct reliability $(C R>0.7)$ were considered to estimate the amount of convergent validity among indicators (Fornell \& Larcker, 1981). All of the Goodness of fit test formulae and variables are included in Appendix.

Internal consistency and scale reliability were calculated using Cronbach's alpha (a), $a \geq 0.70$ was the accepted criteria for the reliability of the scale (Nunnally \& Bernstein, 1994, pp. 264-265). The Pearson correlation coefficient $(r)$ was used to investigate the relationships between the pairs of factors.

\section{Results}

In this section, descriptive statistics and correlation were discussed to confirm that the data set was appropriate for CFA. Then, the fit statistics obtained from the data analyses were discussed to confirm that the model fits well with the empirical data. Convergent and discriminant validity of second-order CFA were assessed to confirm the dimensionality of the model; the three-factors used for measuring CAS-R are truly distinct from each other.

\subsection{Descriptive statistics and correlation}

Mean, SD, SK, and KU of subscale's CAS-R and each item were presented in Table 1, together with abbreviations of all subscales/items. On average, the female students in the Thai university scored higher on "educational aspirations" $(M=23.60, S D=5.16)$ and "achievement aspirations" $(M=23.55$, $S D=4.62)$ than "leadership aspirations" $(M=22.30, S D=5.00)$. The sample size in this study was sufficient to conduct CFA and data was drawn from a normal distribution to values of skewness ranging from -0.12 to $-1.16(S K<|3|)$, and kurtosis values fell from -0.86 to $0.61(K U<|10|)$ (Garson, 2012, pp. 18-19). 
Table 1: The 24-Item of CAS, Means, $S D, S K$, and $K U$

\begin{tabular}{|c|c|c|c|c|c|c|}
\hline \multicolumn{2}{|c|}{ Items } & Abbreviation & $M$ & $S D$ & $S K$ & $K U$ \\
\hline \multicolumn{2}{|c|}{ Achievement aspirations } & Achievement & 23.55 & 4.62 & & \\
\hline 3 & $\begin{array}{l}\text { I want to be among the } \\
\text { very best in my field. }\end{array}$ & CAS_3 & 2.95 & 0.95 & -0.58 & -0.34 \\
\hline 8 & $\begin{array}{l}\text { I want my work to have } \\
\text { a lasting impact on my } \\
\text { field. }\end{array}$ & CAS_8 & 3.03 & 0.91 & -0.70 & -0.10 \\
\hline 9 & $\begin{array}{l}\text { I aspire to have my } \\
\text { contributions at work } \\
\text { recognized by my } \\
\text { employer. }\end{array}$ & CAS_9 & 3.05 & 0.83 & -0.57 & -0.10 \\
\hline 13 & $\begin{array}{l}\text { Being outstanding at } \\
\text { what I do at work is very } \\
\text { important to me. }\end{array}$ & CAS_13 & 2.66 & 0.96 & -0.51 & 0.02 \\
\hline 17 & $\begin{array}{l}\text { I know that I will be } \\
\text { recognized for my } \\
\text { accomplishments in my } \\
\text { field }\end{array}$ & CAS_17 & 2.84 & 0.81 & -0.12 & -0.50 \\
\hline 20 & $\begin{array}{l}\text { Achieving in my career } \\
\text { is not at all important to } \\
\text { me. (reverse scored) }\end{array}$ & CAS_20 & 3.24 & 0.96 & -1.16 & 0.57 \\
\hline 21 & $\begin{array}{l}\text { I plan to obtain many } \\
\text { promotions in my } \\
\text { organization or business. }\end{array}$ & CAS_21 & 2.84 & 1.02 & -0.75 & 0.22 \\
\hline 22 & $\begin{array}{l}\text { Being one of the best in } \\
\text { my field is not important } \\
\text { to me. (reverse scored) }\end{array}$ & CAS_22 & 2.95 & 1.01 & -0.60 & -0.53 \\
\hline \multicolumn{2}{|c|}{ Leadership aspirations } & Leadership & 22.30 & 5.00 & & \\
\hline 1 & $\begin{array}{l}\text { I hope to become a } \\
\text { leader in my career field. }\end{array}$ & CAS_1 & 2.63 & 1.01 & -0.67 & 0.22 \\
\hline 2 & $\begin{array}{l}\text { I do not plan to devote } \\
\text { energy to getting } \\
\text { promoted to a } \\
\text { leadership position in } \\
\text { the organization or } \\
\text { business in which I am } \\
\text { working. (reverse } \\
\text { scored) }\end{array}$ & CAS_2 & 2.89 & 0.95 & -0.44 & -0.56 \\
\hline 4 & $\begin{array}{l}\text { Becoming a leader in my } \\
\text { job is not at all } \\
\text { important to me. } \\
\text { (reverse scored) }\end{array}$ & CAS_4 & 2.82 & 1.02 & -0.42 & -0.75 \\
\hline 5 & $\begin{array}{l}\text { When I am established } \\
\text { in my career, I would } \\
\text { like to manage other } \\
\text { employees. }\end{array}$ & CAS_5 & 2.36 & 1.14 & -0.25 & -0.70 \\
\hline 7 & $\begin{array}{l}\text { I want to have } \\
\text { responsibility for the } \\
\text { future direction of my }\end{array}$ & CAS_7 & 3.08 & 0.81 & -0.57 & -0.02 \\
\hline
\end{tabular}




\begin{tabular}{|c|c|c|c|c|c|c|}
\hline Items & & Abbreviation & $M$ & $S D$ & $S K$ & $K U$ \\
\hline 12 & $\begin{array}{l}\text { organization or business. } \\
\text { Attaining leadership } \\
\text { status in my career is not } \\
\text { that important to me. } \\
\text { (reverse scored) }\end{array}$ & CAS_12 & 2.70 & 1.03 & -0.27 & -0.72 \\
\hline 15 & $\begin{array}{l}\text { I hope to move up to a } \\
\text { leadership position in } \\
\text { my organization or } \\
\text { business. }\end{array}$ & CAS_15 & 2.91 & 0.88 & -0.43 & -0.42 \\
\hline 24 & $\begin{array}{l}\text { I plan to rise to the top } \\
\text { leadership position of } \\
\text { my organization or } \\
\text { business. }\end{array}$ & CAS_24 & 2.91 & 0.90 & -0.56 & -0.03 \\
\hline \multicolumn{2}{|c|}{ Educational aspirations } & Education & 23.60 & 5.16 & & \\
\hline 6 & $\begin{array}{l}\text { I plan to reach the } \\
\text { highest level of } \\
\text { education in my field }\end{array}$ & CAS_6 & 2.98 & 0.90 & -0.33 & -0.86 \\
\hline 10 & $\begin{array}{l}\text { I will pursue additional } \\
\text { training in my } \\
\text { occupational area of } \\
\text { interest. }\end{array}$ & CAS_10 & 3.16 & 0.80 & -0.68 & -0.10 \\
\hline 11 & $\begin{array}{l}\text { I will always be } \\
\text { knowledgeable about } \\
\text { recent advances in my } \\
\text { field. }\end{array}$ & CAS_11 & 2.88 & 0.92 & -0.51 & -0.04 \\
\hline 14 & $\begin{array}{l}\text { I know I will work to } \\
\text { remain current } \\
\text { regarding knowledge in } \\
\text { my field. }\end{array}$ & CAS_14 & 2.90 & 0.82 & -0.27 & -0.57 \\
\hline 16 & $\begin{array}{l}\text { I will attend conferences } \\
\text { annually to advance my } \\
\text { knowledge. }\end{array}$ & CAS_16 & 2.87 & 0.87 & -0.40 & -0.28 \\
\hline 18 & $\begin{array}{l}\text { Even if not required, I } \\
\text { would take continuing } \\
\text { education courses to } \\
\text { become more } \\
\text { knowledgeable. }\end{array}$ & CAS_18 & 2.99 & 0.87 & -0.46 & -0.46 \\
\hline 19 & $\begin{array}{l}\text { I would pursue an } \\
\text { advanced education } \\
\text { program to gain } \\
\text { specialized knowledge } \\
\text { in my field. }\end{array}$ & CAS_19 & 2.92 & 0.96 & -0.80 & 0.61 \\
\hline 23 & $\begin{array}{l}\text { Every year, I will } \\
\text { prioritize involvement in } \\
\text { continuing education to } \\
\text { advance my career. }\end{array}$ & CAS_23 & 2.90 & 0.89 & -0.45 & -0.17 \\
\hline
\end{tabular}

Note. $S E_{S K}=0.13, S E_{K U}=0.27 ; r$ among the items ranged from 0.021 to $0.601 ; K M O=$ 0.925; Bartlett's test of sphericity: $\left(\chi^{2}=3756.332, d f=276, p<0.001\right)$ 
The intercorrelations among the items were not highly correlated ( $r$ ranged from 0.021 to 0.601$)$. The determinant of the correlation matrix was greater than 0.00001 , meaning that there was no multicollinearity. The value of Kaiser-MeyerOlkin $(K M O)$ equaled $0.925(>0.5)$, indicating the sampling was an adequate fit (Kaiser, 1974). In addition to a significant Bartlett's test of sphericity ( $\chi^{2}=$ $3756.332, d f=276, p<0.001)$ that supported the correlation matrix as an identity matrix, signifying that there would be no correlations between the subscales (Field, 2000, p. 607). Showing these statistical values supported the data set, were appropriate for CFA with the maximum likelihood estimation procedure (Hair, Black, Babin, \& Anderson, 2014, p. 628).

\subsection{Confirming the structure of CAS-R}

The second-order factor model yielded the following fit statistics, $\chi^{2}(225, N=$ $301)=435.237, p=0.000, \chi^{2} / d f=1.934, \mathrm{CFI}=0.922, \mathrm{TLI}=0.905, \mathrm{RMSEA}=0.056$ (95\% CI: $0.048 \sim 0.064)$, SRMR $=0.050$, and all the standardized factor loading $(\beta)$ estimates contributed significantly to the measurement of their factors $(p<.01)$ (Figure 2). Judging from the results, the factor structure for second-order CFA was considered to be acceptable as the hypothesized models fitted to the observed data well and the three-factors with 24 -items contributed to an overall CAS-R construct.

\subsection{Item's reliability of second-order CFA}

The reliability of each item (indicator) equals a squared factor loading, which denoted that the percent of item's variance is explained by the factor or latent variable (Brown, 2006, p. 61). Part A of second-order CFA (Figure 2) is the firstorder factor, representing the relations among the factors and their items. The $R^{2}$ values ranged from low to moderate, 0.099 to 0.592. Whereas Part B is the second-order factor, showing that three-factors could explain the focal construct of CAS-R from $87.50 \%$ to $100.00 \%$ of the total variance $\left(R^{2}\right.$ ranged from 0.875 to $1.000)$. These results supported the hypothesis that the CAS-R had a global factor composed of these three-factors with the 24 indicators.

As shown in Figure 2, most of the items in part A had a moderate to strong significant standardized loading with their factors. For the achievement factor, CAS_17 appeared the highest loading and was followed by CAS_13. While CAS -21 scored the lowest loading. The findings indicated that in general, Thai students gave more value to their accomplishments and the being outstanding aspect, whereas the aspect of CAS_21 might be less important. In the leadership factor, CAS_15 was ranked with the highest loading and was followed by CAS_1. While CAS_12 had the lowest loadings. When considered as an education factor, the findings revealed that the item of CAS_14 was ranked the highest loading and was followed by CAS_6. On the other hand, CAS_23 scored the lowest.

However, for achievement factor, the $\beta$ of CAS_8, CAS_20, CAS_21 and CAS_22; for leadership factor, the $\beta$ of CAS_2, CAS_12, and CAS_24 items; for education factor, the $\beta$ of CAS_23 was less than the cutoff of 0.50 , suggesting that it was a rather unreliable indicator of their factors or had a low convergent reliability for 
a factor (Fornell \& Larcker, 1981). This lower cut-off might have occurred due to these items being measured differently from factors.

Part B of Figure 2, it is indicating that "achievement" can explain more variance in CAS-R than leadership and educational aspirations. Therefore, it was concluded that the Thai students were more concerned about "achievement aspirations" than "leadership and educational aspirations."

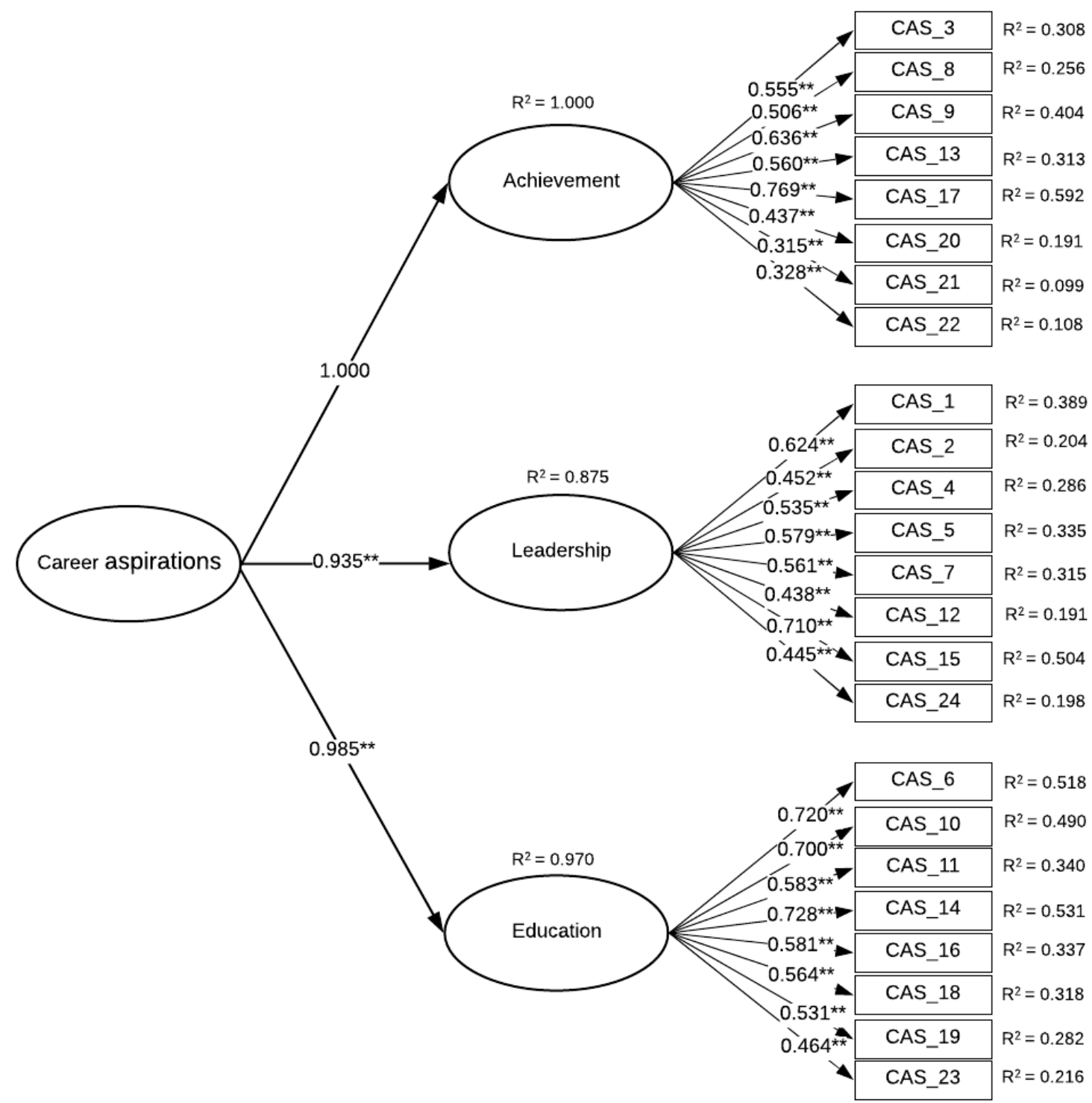

Part B: Second-order factor

Part A: First-order factors

Items/Indicators

Figure 2. The second-order factor model of CAS-R with standardized parameter estimates 
Note: ${ }^{*} p<0.05,{ }^{* *} p<0.01$; The residual variance of achievement was fixed at zero so that it can be identified.

\subsection{Internal consistency and item homogeneity}

The internal consistency estimates of a set of items were assessed by using Cronbach's alpha (a). As presented in Table 2, $a$ of the total scale of CAS-R and three subscales (CAS $=0.925$, achievement $=0.77$, leadership $=0.80$, and education $=0.88$ ) were moderate to high, which referred to measuring the reliability of the concept.

Table 2: Reliability and validity of the factors in the CAS-R measurement model and correlations between subscale

\begin{tabular}{|c|c|c|c|c|c|c|}
\hline \multirow{2}{*}{ Factors } & \multirow{2}{*}{ Alpha (a) } & \multirow{2}{*}{ AVE } & \multirow{2}{*}{$\mathrm{CR}$} & \multicolumn{3}{|c|}{ Correlation matrix } \\
\hline & & & & 1 & 2 & 3 \\
\hline 1.Achievement & 0.769 & 0.645 & 0.746 & $(0.803)$ & & \\
\hline 2 .Leadership & 0.797 & 0.734 & 0.772 & $.775^{* *}$ & $(0.857)$ & \\
\hline 3 .Education & 0.877 & 1.149 & 0.827 & $.786^{* *}$ & $.690^{* *}$ & $1.072))$ \\
\hline 4.CAS & 0.925 & 2.697 & 0.951 & & & \\
\hline
\end{tabular}

\subsection{Convergent and discriminant validity of second-order CFA}

To establish the convergent and discriminant validity of a measurement model, the guidelines of Fornell and Larcker (1981) and Hair et al. (2014, p. 623) were used to assess the validity.

Assessing convergent validity, average variance extracted $(A V E>0.50)$ and composite reliability $(C R>0.70)$ were checked (Fornell \& Larcker, 1981). The $A V E$ represented the average amount of variance that a construct explains in its indicator variables relative to the overall variance of its indicators (Henseler, Ringle, \& Sarstedt, 2015). Whereas the CR of the measurement models, also known as "latent variable reliability" (Fornell \& Larcker, 1981), measured the overall reliability of a set of items loaded on a latent factor (Werts, Linn, \& Jöreskog, 1974). As seen in Table 2, all the factors for CAS-R were well above the .50 threshold for $A V E$ and 0.70 for $C R$ ( $A V E$ ranged from 0.645 to $1.149, C R$ ranged from 0.746 to 0.827 ) and it was concluded that all factors possessed adequate results for convergent validity and appropriate for a multidimensional approach that contained several subscales. All items in this model loaded significantly on their respective latent factors that proved convergent validity for the first-order models (Anderson \& Gerbing, 1988).

To evaluate discriminant validity, which indicates the concept that dissimilar constructs should be different (Burns \& Bush, 1995, p. 275), that is when two scales measuring different constructs-should not be highly correlated. There are two common methods used to assess discriminate validity: (a) if correlation $(r)$ between two factors fall below 0.90, assumes that there is no multicollinearity among factors, indicating discriminant validity (Hair et al., 2014, pp. 619-620), and (b) a comparison of the square root of each construct's $A V E(\sqrt{A V E})$ with the 
inter-factor correlations ( $r$ ) was assessed (Hair et al., 2010, p. 197), $\sqrt{A V E}$ should be greater than $r$, a discriminant validity is supported. Referring to Table 2, not any $\mathrm{r}$ coefficients between factors exceeding 0.90 and $\sqrt{A V E}$ for the three-factors in the diagonal having a larger than its $r$ (off-diagonal) with other factors in the model, supporting evidence of discriminant validity between the factors for CAS-R measurement model. These results implied that the three-factors used for measuring CAS-R were truly distinct from each other. In other words, there was no detection of the collinearity problems among the latent constructs (multicollinearity).

In summary, the 24-item of CAS-R could be adopted in a Thai higher education context and represented by a second-order model of CAS-R. Again, confirming that the three-factor and the 24-item defined the CAS-R construct well.

\section{Discussion}

The second-order factor model had the three subscales grouped into the overall CAS-R factor being more suitable for use in this sample. The results of the second-order CFA indicated that O'Brien's CAS-R could be adopted in Thai female students, which can be represented as the constructs and the item statements describing each of the subscales as the latent factors in the model.

$R^{2}$ and $a$ were computed to test the item's reliability and internal consistency. The results demonstrated good reliability. However, some $\beta$ of items had low convergent reliability for a factor. The convergent and discriminant validity were assessed by using $A V E, C R$, and $r$, supporting evidence of the discriminant validity between the factors for the second-order factor model. Intercorrelations among the three subscales provided preliminary support for the multidimensionality of the instrument.

Furthermore, the findings of the second-order CFA indicated that the female Thai students valued "achievement aspirations" over "educational aspirations," while "leadership aspirations" were valued the least. It may be that "achieving" is the main purpose of studying and working, as achievement is highly emphasized in Thai culture, causing many young women to aspire to succeed in their careers. The reason may be that achievement aspirations are related to long-term success and productivity in female workers (Spangler, 1992). When considering the mean value of "leadership aspirations," it showed that there is less concern than with the item - "hoping to move up to a leadership position in organization or business." This result is consistent with the study by Kim et al. (2015) in the Korean context, which showed that young Korean women scored the lowest in "leadership aspirations". In general, female Thai students did not endorse the view that leadership should be a requirement in a career, although there have been increasing calls for this in the workplace. This may be lead Thai women to have lowered career aspiration (Jarunratanakul \& Jinchang, 2018). This phenomenon also occurs in other Asian countries, so that it is essential to understand women's socialization experiences, which may relate to their career behavior (Hackett \& Betz, 1981). This may be influenced by family characteristics and cultural aspects. Thais are humble and always avoid expressions that reflect 
leadership behavior. According to cross-cultural studies from 76 countries of Hofstede, Hofstede, and Minkov (2010, p. 185), it was concluded that Thai culture has a highly recognized hierarchical authority, high level of misgivings, low individualism, and masculinity. Thai people often compromise, frequently show concern for others, avoid conflict or complaint, which influences their learning styles (Kamolpattana et al., 2015). Such behavior can no doubt lead to women having lower leadership aspirations and the attainment of managerial status in future careers. The findings may also reflect the influence of teaching styles in HEIs and characteristics of the Thais on the level of aspirations and motivations in Thai students, since the pedagogical practice in Thailand generally teaches the students to be passive learners in which they usually keep silence in class (Gunawan, 2016). Similar to the study of Koul, Lerdpornkulrat, and Poondej (2016) found that stereotypes and social preferences affect the career ambitions of Thai students. Therefore, the relatively low weighting reflected in the subscale of "leadership aspirations" is understandable.

This study also found that there were some items in the CAS-R which did not adequately represent the perception of the Thai students. For example, "I plan to obtain many promotions in my organization or business" and "Being one of the best in my field is not important to me (reverse scored)." It could be argued that because not all female Thai students receive an understanding of their position in the organization and might confuse the negative questionnaire. Students may start to believe in the importance of obtaining many promotions after working for some time. Consequently, lecturers, practitioners, counsellors, and parents should continue to encourage students to pursue careers in their areas of interest and to expand their career horizons to leadership positions and continuing education. Especially in HEIs, where professors have a greater impact on the career aspirations of the upper-classes (Walters \& Kremser, 2016).

\section{Future Study and Implication}

Enhancing and building career aspirations can help students grow, increase opportunities, and lead to better chances of success, in both academic and vocational fields. Although this study was only based on three universities in Thailand, this approach is applicable to the use of CAS- $\mathrm{R}$ in other universities with comparable findings. The comparison between male and female students is also of interest, gender differences in career aspirations in Thai culture may be influenced by traditional gender stereotypes (Heilman, 2001) and culture. In support of the factor structure of this model, future direction of research may continue to test the validation of CAS- $R$ in different cultures and consider delving into the influence of independent and mediator variables on career aspirations. Similarly, the study of the effects of career aspirations on professional success should be studied, possibly through cross-validation and longitudinal design. In future research, the relationship between career aspirations and female Thai student's backgrounds (e.g., socioeconomic levels, academic abilities) could be examined and compared with the career aspirations of women from disadvantaged and advantaged families. To be able to give efficacious guidance that can support students of various backgrounds to 
formulate ambitious career goals (McDevitt, Hess, Leesatayakun, Sheehan, \& Kaufeld, 2013).

\section{Conclusion}

The results of the CFA in the study support the validity and reliability of the three-factor structure and 24-item of CAS-R in the female Thai students. Furthermore, the proposition of CAS-R as a second-order factor structure is supported empirically. In a second-order model, the findings of the study reflect that Thai female students prioritized "achievement aspirations" over "educational aspirations," while "leadership aspirations" were valued the least.

In terms of implications, aspiration is one of the critical factors in promoting student success. Although just being aspired is not sufficient, students need to train themselves and be well-developed to have the expertise and skills required to allow them to achieve the desired success (Kintrea et al., 2011, p. 70). Practitioners, mentors, and career counselors can also utilize the CAS to monitor expectations of the female students, raise career aspirations and improve the skills needed to achieve career goals through counseling, student activities, or vocational training.

\section{Acknowledgments}

This work was supported by the Suranaree University of Technology Research and Development Fund. The author would like to thank Prof Dr. O'Brien who permitted to use the CAS-R questionnaire and also thank to Mr. Jetnipit Kunchai and Mr. Narupollawat Chottum for supporting in collecting and recording some part of the data.

\section{References}

Anderson, J. C., \& Gerbing, D. W. (1988). Structural equation modeling in practice: A review and recommended two-step approach. Psychological Bulletin, 103(3), 411423. doi:10.1037/0033-2909.103.3.411

Asparouhov, T., \& Muthén, B. (2018). SRMR in Mplus. Technical Report. May 2, 2018. Retrieved from https://www.statmodel.com/download/SRMR2.pdf

Bethlehem, J. (1999). Cross-sectional research. In H. J. Adèr \& G. J. Mellenbergh (Eds.). Research methodology in the life, behavioural and social sciences. London, UK: Sage.

Brown, T. A. (2006). Confirmatory factor analysis for applied research. New York, NY: Guilford Press.

Browne, M. W., \& Cudeck, R. (1992). Alternative ways of assessing model fit. Sociological Methods \& Research, 21(2), 230-258. doi:10.1177/0049124192021002005

Burns, A. C., \& Bush, R. F. (1995). Marketing research. Englewood Cliffs, NY: PrenticeHall.

Byrne, B. M. (2012). Structural equation modeling with Mplus: Basic concepts, applications, and programming. New York, NY: Routledge.

Callanan, G. A. (2003). What price career success? Career Development International, 8(3), 126-133. doi:10.1108/13620430310471032

Cheng, S., \& Yuen, M. (2012). Education and career aspirations among Chinese high school students: Validation of the career aspiration scale. Asia-Pacific Education Researcher, 21(2), 394-401. Retrieved from http://hub.hku.hk/handle/10722/159974 
Creed, P., Tilbury, C., Buys, N., \& Crawford, M. (2011). The career aspirations and action behaviours of Australian adolescents in out-of-home care. Children and Youth Services Review, 33(9), 1720-1729. doi:10.1016/j.childyouth.2011.04.033

Fernando, R., \& Jayasekara, P. (2015). Determinants of career aspiration: An empirical study on masters of business administration students of selected two national universities in Sri Lanka. Human Resource Management Journal, 3(2), 36-45. doi:10.31357/hrmj.v3i2.2866

Field, A. P. (2000). Discovering statistics using SPSS for Windows: Advanced techniques for beginners. Thousand Oaks, CA: Sage.

Fornell, C., \& Larcker, D. F. (1981). Evaluating structural equation models with unobservable variables and measurement error. Journal of Marketing Research, 18(1), 39-50. doi:10.2307/3151312

Fritz, A. V. (2015). Stereotypical male uniforms, an experimental study on leadership and gender. (Master's Thesis ), Lund University, Lund, Sweden.

Fritz, C., \& van Knippenberg, D. L. (2017). Gender and leadership aspiration: The impact of organizational identification. Leadership \& Organization Development Journal, 38(3), 1018-1037. doi:10.1108/LODJ-05-2016-0120

Garson, G. D. (2012). Testing statistical assumptions. Asheboro, NC: Statistical Associates Publishing.

Gore, J., Holmes, K., Smith, M., Fray, L., McElduff, P., Weaver, N., \& Wallington, C. (2017). Unpacking the career aspirations of Australian school students: Towards an evidence base for university equity initiatives in schools. Higher Education Research \& Development, 36(7), 1383-1400. doi:10.1080/07294360.2017.1325847

Gray, M. P., \& O'Brien, K., M. (2007). Advancing the assessment of women's career choices: The career aspiration scale. Journal of Career Assessment, 15(3), 317-337. doi:10.1177/1069072707301211

Gregor, M. A., \& O'Brien, K. M. (2016). Understanding career aspirations among young women: Improving instrumentation. Journal of Career Assessment, 24(3), 559-572. doi: $10.1177 / 1069072715599537$

Gunawan, J. (2016). Understanding culture in higher education in Thailand. Education for Health, 29(2), 160-161. doi:10.4103/1357-6283.188783

Hackett, G., \& Betz, N. E. (1981). A self-efficacy approach to the career development of women. Journal of Vocational Behavior, 18(3), 326-339. doi:10.1016/00018791(81)90019-1

Hair, J. F., Black, W. C., Babin, B. J., \& Anderson, R. E. (2014). Multivariate data analysis (7th ed.). Edinburgh Gate, UK: Pearson.

Heilman, M. E. (2001). Description and prescription: How gender stereotypes prevent women's ascent up the organizational ladder. Journal of Social Issues, 57(4), 657674. doi:10.1111/0022-4537.00234

Henseler, J., Ringle, C. M., \& Sarstedt, M. (2015). A new criterion for assessing discriminant validity in variance-based structural equation modeling. Journal of the Academy of Marketing Science, 43(1), 115-135. doi:10.1007/s11747-014-0403-8

Hofstede, G., Hofstede, G. J., \& Minkov, M. (2010). Cultures and organizations: Software of the mind (3rd ed.). New York, NY: McGraw-Hill.

Hoppe, A., \& Fujishiro, K. (2015). Anticipated job benefits, career aspiration, and generalized self-efficacy as predictors for migration decision-making. International journal of intercultural relations, 47, 13-27. doi:10.1016/j.ijintrel.2015.03.025

Hu, L.-t., \& Bentler, P. M. (1999). Cut-off criteria for fit indexes in covariance structure analysis: Conventional criteria versus new alternatives. Structural Equation Modeling, 6(1), 1-55. doi:10.1080/10705519909540118

Jarunratanakul, P., \& Jinchang, K. (2018). Does Sexism Affect Thai Women's Psychological and Behavioural Responses? The Stereotype Threat-Buffering 
Effect of Mindfulness. Journal of Pacific Rim Psychology, 12, E26. doi:10.1017/prp.2018.10

Kaiser, H. F. (1974). An index of factorial simplicity. Psychometrika, 39(1), 31-36. doi:10.1007/BF02291575

Kamolpattana, S., Chen, G., Sonchaeng, P., Wilkinson, C., Willey, N., \& Bultitude, K. (2015). Thai visitors' expectations and experiences of explainer interaction within a science museum context. Public Understanding of Science (Bristol, England), 24(1), 69-85. doi:10.1177/0963662514525560

Khampirat, B. (2016). Assessing employers' expectation and satisfaction toward competencies of new graduates in Thailand. Paper presented at the 2016 European Conference on Educational Research (ECER), University College Dublin, Dublin, Ireland.

Khampirat, B. (2017). Development of an instrument for the assessment and strategies for enhancing learning outcomes of undergraduate engineering students. Bangkok, TH: The Thailand Research Fund.

Kim, Y. H., O'Brien, K. M., \& Kim, H. (2015). Measuring career aspirations across cultures: Using the career aspiration scale with young Korean women. Journal of Career Assessment, 24(3), 573-585. doi:10.1177/1069072715599538

Kintrea, K., Clair, R. S., \& Houston, M. (2011). The influence of parents, places and poverty on educational attitudes and aspirations. New York, UK: Joseph Rowntree Foundation.

Kline, R. B. (2011). Principles and practice of structural equation modeling (3rd ed.). New York, NY: Guilford.

Komin, S. (1990). Psychology of the Thai people: Values and behavioral patterns. Bangkok, TH: Research Center, National Institute of Development Administration.

Koul, R., Lerdpornkulrat, T., \& Poondej, C. (2016). Influence of perceived parenting styles on goal orientations and career aspirations of high school science students in Thailand. The International Education Journal: Comparative Perspectives, 15(4), 5665.

Laschinger, H. K. S., Wong, C. A., MacdonaldRencz, S., Burkoski, V., Cummings, G., D'amour, D., . . . Grau, A. (2013). Part 1: The influence of personal and situational predictors on nurses' aspirations to management roles: preliminary findings of a national survey of Canadian nurses. Journal of Nursing Management, 21(2), 217-230. doi:10.1111/j.1365-2834.2012.01452.x

McDevitt, T. M., Hess, C. A., Leesatayakun, M., Sheehan, E. P., \& Kaufeld, K. A. (2013). A cross-sectional study of career aspirations in Thai children in an international school in Bangkok. Journal of Career Development, 40(6), 531-550. doi: $10.1177 / 0894845312470025$

McKenzie, S., Coldwell-Neilson, J., \& Palmer, S. (2016). Informing the career development of IT students by understanding their career aspirations and skill development action plans. Australian Journal of Career Development, 26(1), 14-23. doi:10.1177/1038416217697972

Nunnally, J. C., \& Bernstein, I. H. (1994). Psychometric theory (3rd ed.). New York, NY: McGraw-Hill.

O'Brien, K. M. (1996). The influence of psychological separation and parental attachment on the career development of adolescent women. Journal of Vocational Behavior, 48(3), 257-274. doi:10.1006/jvbe.1996.0024

Ona, A. (2015). Professional aspirations in students with technical talent. Procedia - Social and Behavioral Sciences, 191, 1881- 1885. doi: 10.1016/j.sbspro.2015.04.239

Powell, L., Amsbary, J., \& Hickson, M. (2014). The Wai in Thai culture: Greeting, statusmarking and national identity functions. Journal of Intercultural Communication, 34(March 2014). https://www.immi.se/intercultural/nr34/powell.html

Schreiber, J. B., Nora, A., Stage, F. K., Barlow, E. A., \& King, J. (2006). Reporting structural equation modeling and confirmatory factor analysis results: A review. The Journal of Educational Research, 99(6), 323-338. doi:10.3200/JOER.99.6.323-338 
Sewell, W. H., Haller, A., \& Portes, A. (1969). The educational and early occupational attainment process. American Sociological Review, 34(1), 82-92. doi:10.2307/2092789

Shi, D., Maydeu-Olivares, A., \& DiStefano, C. (2018). The relationship between the standardized root mean square residual and model misspecification in factor analysis models. Multivariate Behavioral Research, 53(5), 676-694. doi:10.1080/00273171.2018.1476221

Sidiropoulou-Dimakakou, D., Mylonas, K., \& Argyropoulou, K. (2015). Self-efficacy in career planning: A new approach to career exploration. International Journal of Learning, Teaching and Educational Research, 11(2), 40-54.

Spangler, W. D. (1992). Validity of questionnaire and TAT-measures of need for achievement: Two meta-analyses. Psychological Bulletin, 112, 140-154. doi:10.1037/0033-2909.112.1.140

Ullman, J. B., \& Bentler, P. M. (2003). Structural equation modeling. In J. A. Schinka \& W. F. Velicer (Eds.), Handbook of psychology: Research methods in psychology, Vol. 2 (p. 607-634). John Wiley \& Sons Inc.

Walters, G. D., \& Kremser, J. (2016). Differences in career aspirations, influences, and motives as a function of class standing: An empirical evaluation of undergraduate criminal justice majors. Journal of Criminal Justice Education, 27(3), 312-323. doi:10.1080/10511253.2015.1125516

Weeranakint, W., \& Sungsanit, M. (2009). The Relations between work-family conflict, self-efficacy, social support, and career aspirations of women in managerial positions, in Nakhon Ratchasima Province. Suranaree Journal of Social Science, 3(2), 91-108. Retrieved from https://www.tcithaijo.org/index.php/sjss/article/view/23936/20376

World Economic Forum. (2019). The global competitiveness report 2019. Geneva, CH: World Economic Forum.

Werts, C. E., Linn, R. L., \& Jöreskog, K. G. (1974). Intraclass reliability estimates: Testing structural assumptions. Educational and Psychological Measurement, 34(1), 25-33. doi:10.1177/001316447403400104

Wu, H. M. (2007). Self-efficacy, work-family conflict, social support, gender role attitude and role model as antecedents of career aspiration among women in middle management. (Master's Thesis), Universiti Putra Malaysia, Putra, Malaysia. 


\section{Appendix- Approximate Fit Indexes}

\begin{tabular}{|c|c|c|}
\hline Fit Index & The Formula & $\begin{array}{l}\text { The Statistical Hypothesis } \\
\text { Test for Model Close Fit }\end{array}$ \\
\hline $\begin{array}{l}\text { The } \\
\text { comparative } \\
\text { fit index } \\
\text { (CFI) }\end{array}$ & $\begin{array}{l}\qquad \text { CFI }=1-\frac{\chi 2_{M}-d f_{M}}{\chi 2_{B}-d f_{B}} \\
\text { Where } \\
\quad \begin{array}{l}\mathrm{M}=\text { The researcher's specified model } \\
\mathrm{B}=\text { The baseline model (statistical null } \\
\text { model) }\end{array} \\
\text { (Hair et al., 2014, p. 595; Kline, 2011, p. 208) }\end{array}$ & $\begin{array}{l}\mathrm{H}_{0}: C F I \geq 0.90 \\
\mathrm{H}_{\mathrm{a}}: \text { CFI }<0.90 \\
\text { Null model: All latent } \\
\text { variables in the model are } \\
\text { uncorrelated } \\
\text { (null/independence model) } \\
\text { (Hu \& Bentler, 1999; } \\
\text { Ullman \& Bentler, 2003, p. } \\
\text { 671) }\end{array}$ \\
\hline $\begin{array}{l}\text { The Tucker- } \\
\text { Lewis index } \\
\text { (TLI) }\end{array}$ & $\begin{array}{l}\mathrm{TLI}=\frac{\frac{\chi^{2}}{d f}(\text { Null Model })-\frac{\chi^{2}}{d f}(\text { Proposed Model })}{\frac{\chi^{2}}{d f}(\text { Null Model })-1} \\
\text { (Hair et al., 2014, p. 595) } \\
\text { (TLI also known as Non-Normed Fit Index - } \\
\text { NNFI) }\end{array}$ & $\begin{array}{l}\mathrm{H}_{0}: \text { TLI } \geq 0.90 \\
\mathrm{H}_{\mathrm{a}}: \text { TLI }<0.90 \\
(\text { Hu \& Bentler, 1999) }\end{array}$ \\
\hline $\begin{array}{l}\text { The root } \\
\text { mean square } \\
\text { error of } \\
\text { approximati } \\
\text { on (RMSEA) }\end{array}$ & $\begin{array}{l}\text { RMSEA }=\sqrt{\frac{\left(\chi^{2}{ }_{M}-d f_{M}\right)}{d f_{M}(N-1)}} \\
\text { where } \\
\qquad \begin{aligned} \mathrm{N}= & \text { the sample size } \\
d f_{M}= & \text { the degrees of freedom of the } \\
& \text { researcher's model }\end{aligned} \\
\qquad(\text { Kline, 2011, p. 205) }\end{array}$ & $\begin{array}{l}\mathrm{H}_{0}: \text { RMSEA } \leq 0.05 \\
\mathrm{H}_{\mathrm{a}}: \text { RMSEA }>0.05 \\
\\
\text { (Browne \& Cudeck, 1992) }\end{array}$ \\
\hline $\begin{array}{l}\text { The } \\
\text { standardize } \\
\text { d root mean } \\
\text { square } \\
\text { residual } \\
\text { (SRMR) }\end{array}$ & $\begin{array}{l}\text { SRMR }=\sqrt{\frac{p}{\frac{p(p+1)}{2+p}}} \\
\text { where } S \text { is } \\
\qquad S=\sum_{j=1}^{p} \sum_{k=1}^{j-1}\left(\frac{s_{j k}}{\sqrt{s_{j j} s_{k k}}}-\frac{\sigma_{j k}}{\sqrt{\sigma_{j j} \sigma_{k k}}}\right)^{2}+ \\
\sum_{j=1}^{p}\left(\frac{m_{j}}{\sqrt{s_{j j}}}-\frac{\mu_{j}}{\sqrt{\sigma_{j j}}}\right)^{2}+\sum_{j=1}^{p}\left(\frac{s_{j j}-\sigma_{j j}}{s_{j j}}\right)^{2} \\
p=\text { the number of observed variables in the } \\
\text { model } \\
s_{j k} \text { and } \sigma_{j k}=\text { the sample and the model- } \\
\text { estimated covariance between the } j-\text { th } \\
\text { and } k \text {-th variables. }\end{array}$ & $\begin{array}{l}\mathrm{H}_{0}: \mathrm{SRMR} \leq 0.08 \\
\mathrm{H}_{\mathrm{a}}: \mathrm{SRMR}>0.08 \\
\text { (Hu \& Bentler, 1999; Shi, } \\
\text { Maydeu-Olivares, \& } \\
\text { DiStefano, 2018) }\end{array}$ \\
\hline
\end{tabular}


$m_{j}$ and $\mu_{j}=$ the sample and the modelestimated mean of the $j$-th variable

Note: Formula for the general SEM model with continuous dependent variables.

(Asparouhov \& Muthén, 2018;

Shi, Maydeu-Olivares, \& DiStefano, 2018) 